\title{
Thank you to Professor Ludwig
}

\author{
Klaus Diedrich
}

Published online: 17 August 2010

(C) Springer-Verlag 2010

After 30 years of service as Coordinating Editor of Archives of Gynecology and Obstetrics, Hans Ludwig is gradually withdrawing from this position. Here today, on behalf of the entire Editorial Board, I would like to express sincere gratitude for his exceptional work in leading the journal with great commitment over so many years. The journal is the official organ of the German Society of Gynecology and Obstetrics, and has made a decisive contribution in improving the standing of German gynecology and obstetrics throughout the world. Currently, the journal has a rising impact factor, and four or five manuscripts are received each day. The large majority of the submitted papers are of such a quality as to necessitate a strict selection process, which is certainly to the benefit of the journal.

Now is the time to thank Hans Ludwig on behalf of the Editorial and Advisory Boards and also Springer-Verlag. For me it is a great honour to be following in his footsteps and taking up the role of Coordinating Editor from 1st October. I know that it will be difficult to fill the shoes of my predecessor, but I am nevertheless ready and willing to try to grow into them. I am delighted that Professor Ludwig, as Editor Emeritus, will lend both the journal and myself his continuing support in the future. This is essential in ensuring that the transitional period proceeds smoothly and unobtrusively. Aside from this unavoidable change, the Editorial Board will continue to comprise the same members who have worked together so successfully in recent years.

At this point I would like to thank you, dear Hans, the Editorial Board and Springer-Verlag for having the confidence to entrust to me this responsible task.

I shall always be ready to listen to your loyal and friendly advice, and I shall do my best to ensure that the journal remains on a sound and prosperous course.

October 2010

Klaus Diedrich

(Coordinating Editor)

On behalf of the Editorial Board and the Advisory Board
K. Diedrich $(\bowtie)$

Klinik für Frauenheilkunde und Geburtshilfe, Universitätsklinikum Schleswig-Holstein, Ratzeburger Allee 160, 23538 Lübeck, Germany e-mail: klaus.diedrich@uk-sh.de 